\title{
Analisis Faktor Terjadinya Duplikasi Berkas Rekam Medis Ruangan Filling Di RSUD Tais Kabupaten Seluma
}

\author{
Yoki Hermansyah \\ Akkes Sapta Bakti Bengkulu \\ Yokihermansyah5@gmail.com
}

\begin{abstract}
ABSTRAK
Ditemukan diruangan penyimpanan berkas rekam medis pasien belum mengunakan petunjuk keluar tracer (outguide), dan dari data observasi didapatkan hasil 285 berkas rekam medis yang terjadinya duplikasi.Tujuan penelitian ini adalah untuk mengetahui analisis faktor pendukung penggunaan tracer (outguide) ruangan filling di RSUD Tais Kabupaten Seluma. Jenis penelitian yang digunakan observasional dengan rancangan deskripif, populasi dalam penelitian ini ada dua yaitu petugas di unit rekam medis 5 orang dan berkas rekam medis berjumlah 700 berkas, dengan sampel 5 orang petugas dan 233 berkas rekam medis dengan pengambilan sampel secara Stratified Random Sampling. Menggunakan data primer dan sekunder yang diolah secara univariat.Penelitian ini dilaksanakan pada bulan juni sampai juli tahun 2016 di ruangan rekam medis RSUD Tais Kabupaten Seluma. Dari 12 petugas rekam medis di RSUD Tais Kabupaten Seluma hanya 1 orang yang berlatar belakang D-III rekam medis, dan hasil observasi dari 233 berkas rekam medis yang diamati didapatkan 49 berkas rekam medis yang terjadinya duplikasi, sehingga jika dipersentase kan 21,03\%. Diharapkan kepada kepala ruangan rekam medis untuk penambahan Sumber Daya Manusia yang berlatar belakang pendidikan DII-rekam medis agar kinerja petugas rekam medis dapa berjalan sesuai standar prosedur yang ada dan dilakukanya perencanaan pembuatan tracer agar berkas rekam medis yang dipinjam dapat terkontrol keluar masuknya.
\end{abstract}

\section{Kata kunci $\quad$ : Faktor, Tracer, Duplikasi}

\section{PENDAHULUAN}

Rumah sakit merupakan suatu sarana pelayanan kesehatan yang menyelengarakan upaya kesehatan kepada masyarakat, baik rawat jalan, rawat inap, maupun gawat darurat. Pelayanan kesehatan yang diberikan kepada masyarakat mulai dari pendaftaran sampai dengan pengolahan data hasil pelayanan kesehatan sehingga menghasilkan berbagai macam informasi. Informasi tersebut dapat digunakan rumah sakit dalam memberi pelayanan dan pengambilan keputusan untuk meningkatkan kualitas pelayanan rumah sakit tersebut (Depkes RI, 2006).

Pelayanan rumah sakit bertujuan untuk meningkatkan darajat kesehatan masyarakat. Pelayanan kesehatan di rumah sakit terdiri dari beberapa pelayanan kesehatan. salah satunya adalah pelayanan rekam medis (Rustiyanto,2010). 
Rekam medismempunyai peran yang sangat penting dibidang administrasi dan keterampilan dibidang pekerjaan rekam medis. Perkembangan dan kemajuan rekam medis tergantung pada pelayanan rekam medis kerena merupakan ujung tomak awal dimulainya aktivitas pelayanan kesehatan yang harus diberikan secera optimal. Adapun tenaga kesehatan yang berhak mengisi rekam medis antara lain dokter umum, petugas rekam medis, dan perawat yang merawat pasien dirumah sakit. Rekam medis adalah keterangan baik tertulis atau terekam tentang identittas pasien, anamnesis, pemeriksaan fisik, laboratorium, diagnosa, serta segala pelayanan dan tindakan medis yang diberikan kepada pasien, dan pengobatan baik secara dirawat inap, rawat jalan atau mendapatkan pelayanan gawat darurat (Depkes RI, 2006).

Dalam penyelengaraaan rekam medis telah diatur dalam surat keputusan menteri kesehatan RI No 749/a/Menkes/XII/1982 rekam medis dinilai baik apabila pencatatan dan pengolahan data melakukan tugasnya dengan baik pula. Sedangkan menurut Permenkes No. 269/menkes/per/2008 rekam medis adalah berkas yang berisikan catatan dan dokumen tentang pasien, pemeriksaan, pengobatan, tindakan dan pelayanan lain yang telah diberikan kepada pasien pada pasien. Rekam medis adalah siapa, apa, dimana dan baimana perawatan pasien selamam dirumah sakit, untuk melengkapi data rekam medis memiliki data yang cukup tertulis dalam rangkaian kegiatan guna menghasilkan suatu diagnosis, jaminan, pengobatan dan hasil akhir.

Rekam medis akan terlaksana dengan baik apabila bagian pengelolaan data dan pencatatan rekam medis melaukan tugasnya dengan baik. Salah satunya adalah pengelolahan data dibagian filiing. Filing adalah unit kerja rekam medis yang diakreditasi oleh Departemen Kesehatan yang berfungsi sebagai tempat pengaturan dan penyimpanan dokumen atas dasar sistem penataan tertentu melalui prosedur yang sistematis sehingga sewaktu-waktu dibutuhkan dapat menyajikan secara tepat dan cepat, maka dibutuhkan Petunjuk keluar tracer (outguide) suatu alat yang penting untuk mengawasi penggunaan rekam medis. Petunjuk keluar ini digunakan sebagai penganti pada tempat rekam medis yang diambil dari rak penimpanan dan tetap berada dirak tersebut sampai rekam medis yang diambil kembali (Savitri, 2011).

Hasil penelitian Asmono (2014) bahwa faktor-faktor penyebab tidak menggunkan tracer (outguide) dibagian penyimpanan berkas rekam medis di Rumah Sakit Mata 
Dr. Yap Yogyakarta yaitu sumber daya manusia (SDM), yaitu petugasnya tergesagesa, sarana dibagian penyimpanan yaitu rak penyimpanan sudah penuh dan Prosedur Tetap pengambilan dan penyimpanan rekam medis terkait penggunaan tracer (outguide) yang dijalankan. Dampak tidak menggunakan tracer (outguide) dibagian penyimpanan berkas rekam medis di Rumah Sakit Mata Dr. Yap Yogyakarta yaitu missfile dan berkas rekam medis sulit terlacak.

Selain itu, berdasarkan hasil penelitian vita mardiani (2013) tinjaun tingkat kejadian missfile dan faktor-faktor penyebabnya di fiiling RSUD Sunan Kalijaga Kabupaten Demak Triwulan 1 Tahun 2013, karena banyaknya dokumen yang harus diambil setiap harinya, dari survei pada bulan desember 2012 ditemukan bahwa terdapat 209 kejadian missfile dari 1655 yang ada di 30 kotak file. Persentase tingkat terjadinya missfile mencapai $12 \%$, hall ini dikarenakan tidak adanya petunjuk keluar tracer (outguide) dan kode warna untuk mempermudah pengembalian DRM dan minimnya fasilitas yang ada diruangan filling.

Rumah Sakit Umum Daerah (RSUD) Tais adalah rumah sakit pemerintah dengan tipe $\mathrm{D}$, di unit rekam medis memiliki 12 petugas dalam memberi pelayanan setiap harinya, namun hanya 1 orang yang berpendidikan D3 rekam medis. sistem penyimpanan yang digunakan adalah desentralisasi, sistem penomoran yang digunakan unit numbering system, dan sistem penjajaran Terminal Digit Filling.

Berdasarkan hasil pra-penelitian saat melakukan praktek pada bulan maret 2016 di RSUD Tais Kabupaten Seluma ditemukan diruangan penyimpanan berkas rekam medis pasien belum mengunakan petunjuk keluar tracer (outguide, dan dari data observasi didapatkan 285 berkas rekam medis yang terduplikasi, hilang dan terlapisdari 700 berkas rekam medis yang ada di 7 box tempat penyimpanan berkas rekam medis pada tahun 2014, dipersentasekan 35\% nomor rekam medis yang terduplikasi yaitu dengan nomor rekam medis yang sama tapi identitasnya yang berbeda, contohnya nama Ny. Juita nomor rekam medis 00-80-46 dengan Ny. Sinta nomor rekam medisnya 00-80-46. Oleh karena itusulitnya pencarian berkas rekam medis ketika pasien ingin kontrol uang, dikarenakan satu nomor rekam medis memiliki dua identitas sehingga pihak rumah sakit harus memutuskan salah satnya diganti dengan nomor rekam medis baru. Hal ini diakibatkan tidak adanya petunjuk keluar trecer (outguide) pada penyimpanan 
berkas rekam medis di RSUD Tais Kabupaten seluma. Sehingga banyak foktor yang mendukung untuk pembuatan tracer (outguide) di ruangan filling, maka dapat dicari jalan keluar dari masalah tersebut dan dapat menjadi bahan masukan bagi rumah sakit supaya dalam pemeliharaan dokumen rekam medis dapat berjalan lebih baik serta dapat meminimalisasi kejadian duplikasi nomor rekam medis.

Berdasarkan latar belakang diatas penulis tertarik untuk melakukan penelitian dengan judul"Analisis faktor terjadinya duplikasi berkas rekam medis di ruangan filling di RSUD Tais Kabupaten Seluma “.

\section{METODE PENELITIAN}

\section{A. Jenis dan Rancangan Penelitian}

Jenis penelitian ini adalah observasional dengan rancangan deskriftif yang dilakukan melalui pengamatan (observasi) baik secara langsung maupun tidak langsung tanpa ada perlakuan atau intervasi. (Hidayat, 2010).

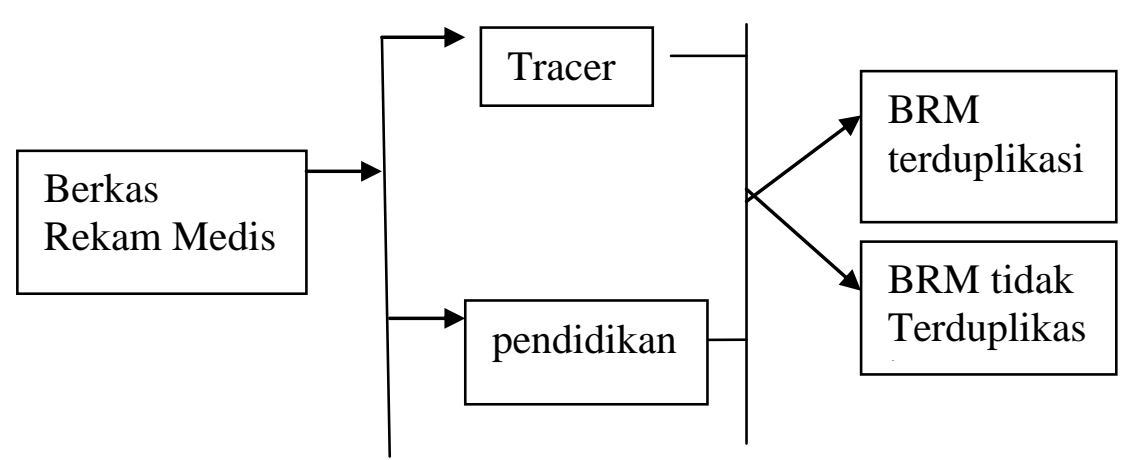

\section{B. Waktu dan Tempat Penelitian}

Penelitian akan dilaksanakan pada bulan Juni-juli 2016. di ruangan pendaftaran dan penyimpanan berkas rekam medis di RSUD Tais Kabupaten Seluma.

\section{Subyek Penelitian}

1. Populasi

Populasi adalah sekelompok subjek atau data dengan karakteristik tertentu. Dalam penelitian ini yang menjadi populasi yaitu yang pertamaberkas rekam medis yang berjumlah 700 berkas rekam medis, 
yang kedua yaitu petugas diruangan penyimpanan berjumlah 4 orang dan kepala ruangan Rekam Medis berjumlah 1 orang.

2. Sampel

Sampel adalah sebagian dari populasi yang dipilih dengan cara tertentu hingga dianggap dapat mewakili populasinya (Sastrosmoro

Diketahui,

$$
\begin{aligned}
\mathrm{N} & =700 \\
\mathrm{~d}= & 5 \%(0,05) \\
n & =\frac{\mathrm{N}}{\mathrm{n}+\mathrm{N}\left(\mathrm{d}^{2}\right)} \\
n & =\frac{700}{1+700(0.05)^{2}} \\
& =\frac{700}{1+700(0.0025)} \\
& =\frac{700}{1+2} \\
& =233
\end{aligned}
$$

Keterangan :

$\mathrm{n}=$ Jumlah sampel

$\mathrm{N}=$ Jumlah Populasi

$\mathrm{d}=$ Tingkat keakurasian atau kepercayaan 5\%(0,05)

Jadi, sampel yang dibutuhkan dalam penelitian ini adalah 233berkas rekam medis.

3. Teknik Pengambilan Sampel

Teknik pengambilan sampel ada 2 yaitu yang petama untuk mengetahui data yang ingin diambil yaitu pendidikan dan tracer
\& Ismael, 2010). Sampel pada penelitian ini terdiri dari 700 berkas rekam medis dari 7 box penyimpanan berkas rekam medis dan 4 petugas rekam medis dan 1 orang kepala ruangan rekam medis, berkas rekam medis menggunakan rumus solvin yaitu : 
populasi menjadi sampel. Yang ke dua untuk mengetahui berkas rekam medis yang terduplikasi dengan menggunakan rumus Stratified Random Sampling yaitu pengambilan sampel dimana poulasi yang bersifat heterogen dibagi dalam lapisanlapisan (stara). Jumlah populasi berkas rekam medis dalam satu rak terdapat 7 box berjumlah 700 BRM. Berdasarkan perhitungan sampel didapatkan jumlah sampel 233 BRM yang akan diteliti, sehingga data yang akan diambil untuk mewakili 7 box tersebut yaitu:

Box $1=100$ BRM, maka $(100 / 700 \times 233)=33$

BRM

Box $2=100$ BRM, maka $(100 / 700 \times 233)=$

\section{BRM}

Box $3=100$ BRM, maka $(100 / 700 \times 233)=$

\section{BRM}

Box $4=100$ BRM, maka $(100 / 700 \times 233)=$

\section{BRM}

Box $5=100$ BRM, maka $(100 / 700 \times 233)=$

\section{BRM}

Box $6=100$ BRM, maka $(100 / 700 \times 233)=$

\section{BRM}

Box $7=100$ BRM, maka $(100 / 700 \times 233)=$

\section{BRM}

Jadi, keseluruhan dari 7 box dapat mewakili sampel yang dibutuhkan yaitu 233, dan masing-masing box diambil secara sistematik sampling yaitu dengan kelipatan 3 $(100 / 33=3)$.

\section{Variabel Penelitian}

Menurut Riwidikdo (2009), variabel diartikan satribut dari subjek penelitian atau objek yang akan diteliti yang bervariasi antara satu subjek atau objek yang satu dengan yang lainya. Variabel bebas (Independen) adalah variabel yang mempengaruhi prediktor, resiko atau kausa. Dalam penelitian ini yang menjadi variabel bebas (Independen) adalah berkas pendidikan dan tracer. Variabel terikat (dependen) adalah variabel yang dipengaruhi oleh variabel bebas. Dalam penelitian ini terikat (dependen) adalah duplikasi berkas rekam medis.

\section{E. Definisi Operassional}

Definisi Operasioal adalah penjelasan tentang pengertian variabel secara operasional (saat pengambilan data di lapangan), bagaimana suatu variabel akan diukur serta alat ukur yang digunakan, kategori data (indikator data) dan skala ukur. 
Tabel 3.1. Tabel Observasi

\begin{tabular}{|c|c|c|c|c|c|}
\hline Variabel & Pengertian & Alat Ukur & Cara Ukur & Hasil Ukur & $\begin{array}{l}\text { Skala } \\
\text { Ukur }\end{array}$ \\
\hline $\begin{array}{l}\text { Duplikasi } \\
\text { nomor } \\
\text { RM }\end{array}$ & $\begin{array}{lrr}\text { Terjadi } & \text { pengandaan } & \text { nomor } \\
\text { BRM }(1 \text { nomor } & \text { RM } & \text { dimiliki } \\
\text { Oleh } 2 & \text { orang } & \text { pasien } \\
\text { terduplikasi } & \text { dan } & \text { tidak } \\
\text { terduplikasi } & & \end{array}$ & $\begin{array}{l}\text { Lembar } \\
\text { Observasi }\end{array}$ & Observasi & $\begin{array}{ll}\text { 1: } & \\
& \quad \text { terdup } \\
& \text { likasi } \\
0: & \text { tidak } \\
& \text { terduplika } \\
& \text { si }\end{array}$ & $\begin{array}{l}\text { Nomin } \\
\text { al }\end{array}$ \\
\hline $\begin{array}{l}\text { Pendidika } \\
\mathrm{n}\end{array}$ & $\begin{array}{l}\text { Tingkat pendidikan formal yang } \\
\text { telah ditempuh oleh seseorang }\end{array}$ & $\begin{array}{l}\text { Pedoman } \\
\text { wawancara }\end{array}$ & $\begin{array}{l}\text { wawancar } \\
\text { a }\end{array}$ & $\begin{aligned} 1 & : \text { DIII } \\
& \text { RMIK } \\
0: & \text { Tidak } \\
& \text { DIII } \\
& \text { RMIK }\end{aligned}$ & $\begin{array}{l}\text { Nomin } \\
\text { al }\end{array}$ \\
\hline Tracer & $\begin{array}{lr}\text { Outguide/petunjuk } & \text { keluar } \\
\text { BRM, untuk } & \text { mengetahui } \\
\text { keberadaan BRM } & \end{array}$ & $\begin{array}{l}\text { Pedoman } \\
\text { wawancara }\end{array}$ & $\begin{array}{c}\text { wawancar } \\
\text { a }\end{array}$ & Narasi & - \\
\hline
\end{tabular}

\section{F. Instrumen Penelitian}

Instrumen penelitian bukan satu-satunya penentuan bahwadata yang diambil akan akurat, ada hal lain yang mempengaruhi keakuratan data yang kita ambil yaitu teknik pengambilan data. Alat yang digunakan dalam penelitian ini adalah llembar observasi dan pedoman wawancara.

\section{G. Teknik Pengumpulan Data dan} Analisa Data

1. Teknik Pengumpulan data

a. Data Primer
Data primer yaitu data yang diambil secara langsung diambil dari objek peneitian. Dalam penelitian ini yang menjadi data primer adalah peneliti melakukan wawancara tentang pendidikan dan tracer petugas rekam medis.

b. Data Sekunder

Data sekunder adalah data yang diperoleh penenliti dari sumber yang ada. Dalam hal ini penelitian melakukan telaah nomor berkas rekam medis pasien rawat jalan yang tersusun di dalam sub rak 
penyimpanan berkas rekam medis rawat jalan.

2. Pengolahan Data

a. Editing adalah melihat berkas rekam medis apakah terdapat satu nomor yang sama atau berbeda.

b. Coding yaitu peng"kodean"mengubah data (jawaban responden) berbentuk kata-kata menjadi data atau bilangan. 1 : Duplikat, 0 : Tidak Duplikat, 1 : DIII RMIK, 0 : Tidak DIII RMIK.

c. Cleaning, setelah semua data selesai dimasukan perlu di cek kembali untuk melihat kemungkinan adanya kesalahan kode, kemungkinan ada data yang hilang dan mengecek konsistensi data.

\section{H. Analisa Data}

Teknik analisa terkumpul dilakukan analisis secara univariat yaitu distribusi frekuensi narasi. Analisis univariat bertujuan untuk menjelaskan/mendeskripsikan karakteristik masing-masing variabel (Hastono, 2007). Analisa data ini menggunakan tabel dan narasi. Duplikasi nomor rekam medis disajikan dalam bentuk tabel dan pendidikan dan tracer disajikan dalam bentuk narasi.

HASIL DAN PEMBAHASAN

A. Jalannya Penelitian

Vol. 3 No. 1 Juni 2017 : 25-37
Penelitian ini dilakukan beberapa tahap sebagai berikut :

1. Tahapan bersiapan

Tahapan persiapan yang dilakukan oleh peneliti dalam penelitian ini dimulai dari menemukan masalah yang terjadi di lapangan, merumuskan pertanyaan penelitian, mencari literatur yang relevan, dan mengembangkan instrument penelitian (observasi).

2. Tahap pelaksanaan

Setelah proposal penelitian disetujui, peneliti mengurus izin penelitian ke instansi terkait, mempersiapkan bahan untuk observasi, mengatur jadwal untuk melakukan penelitian, mempersentasikan tujuan penelitian di RSUD Tais, melakukan pengumpulan data dengan cara melakukan observasi secara langsung pada ruangan penyimpanan berkas rekam medis.

3. Tahapan penyusunan laporan Setelah data terkumpul kemudian melakukan pengelolahan data dan analisis data dengan menyusun pembahasan hasil penelitian dan laporan penelitian.

\section{B. Hasil Penelitian}

\section{Gambaran Rumah Sakit Umum Daerah Tais}

RumahSakitUmum Daerah (RSUD)

TaisadalahRumahSakitUmum Daerah (RSUD) 
yang menjadi Rumah Sakit Rujukan satusatunya berada di Kabupaten Seluma, yang berdiri sejak tahun 2005 dan diresmikan penggunaannya pada 3 Agustus 2006 oleh Bupati Seluma H. Murman Effendi, SE danpertama kali beroperasiterdiridari 3 (tiga) gedung utama antara lain Unit Gawat Darurat, Gedung Poliklinik, dan Gedung Administrasi. Rumah Sakit Umum Daerah (RSUD) Tais merupakan Rumah Sakit tipe D, dengan rata-rata kunjungan pasien perhari sekitar 30-50 pasien rawat jalan dan 5-10 pasien rawat inap.Rumah Sakit Umum Daerah (RSUD) Tais melaksanakan upaya kesehatan secara berdaya guna dan berhasil guna dengan mengutamakan penyembuhan, pemulihan, serta melakukan rujukan secara kompherensip.

\section{Analisis Univariat.}

\section{a. Distribusi Frekuensi Berkas Rekam Medis}

\section{Yang duplikasi}

Berdasarkan hasil observasi yang telah peneliti lakukan di ruangan penyimpanan berkas rekam medis dengan teknik penambilan sampel secara sistematik sampling dari 233 berkas rekam medis, ada 49 berkas rekam medis yang terjadinya duplikasi, yang dapat dilihat pada tabe 4.1

Tabel 4.1 analisis berkas rekam medis yang terduplikasi dan tidak terduplikasi

\begin{tabular}{cccc}
\hline No & Variabel & Jumlah (n) & Persentase (\%) \\
\hline 1 & Duplikasi & 49 & $21,03 \%$ \\
& & & \\
\hline 2 & Tidak & 184 & $78,96 \%$ \\
& Duplikasi & & \\
& & & $100 \%$
\end{tabular}

\section{Sumber : Data terolah, 2016}

Berdasarkan tabel data duplikasi nomor rekam medis diruangan penyimpanan berkas rekam medis pasien dari 233 berkas rekam medis didapatkan 49 berkas rekam medis yang terjadinya duplikasi (21,03\%), yang tidak terjadinya duplikasi yaitu 184 dari 233 berkas rekam medis $(78,96 \%)$.

\section{b. Distribusi frekuensi tingkat pendidikan petugas}

Vol. 3 No. 1 Juni 2017 : 25-37
Dari hasil wawancara dengan kepala ruangan rekam medis dan petugas penyimpanan bahwa pada bagian rekam medis di rumah sakit umum daerah tais terdapat 12 orang petugas rekam medis. Masing-masing petugas yang berlatar belakang pendidikan D3 rekam medis hanya 1 orang, yang lainya berlatar belakang pendidikan S1 kesehatan 2 orang, D3 kesehatan 5 orang, pendidikan 2 orang, SMA 2 orang. Oleh karena itu dengan sedikitnya petugas rekam 
medis yang berlatar belakang pendidikan D3 rekam medis dapat menjadi salah satu faktor tidak adanya tracer diruangan penyimpanan.

Selain itu SDM dapat mempengaruhi pelaksanaan pengelolahan rekam medis khususnya pada bagian penyimpanan adalah sarana yang belum

memadai, salah satunya yaitu kurangnya rak penyimpanan berkas rekam medis. Berdasarkan hasil wawancara kepada petugas rekam medis bahwa faktor tidak adanya tracer diruangan penyimpanan berkas rekam medis adalah sarana belum memadai.

\section{c. Penggunaan Tracer (outguide)}

Berdasarkan wawancara yang dilakukan di Rumah Sakit Umum Daerah Tais bahwa diruangan penyimpanan berkas rekam medis petugas tidak menggunakan petunjuk keluar tracer (outguide) sebagai penganti berkas rekam medis yang dipinjam atau dikeluarkan dari rak penyimpanan mereka hanya menggunakan buku register sebagai pengendali berkas rekam medis yang keluar dari rak penyimpanan.Hal ini dikarenakan di Rumah Sakit Umum Daerah Tais sarana dan prasarananya belum memadai untuk pembuatan tracer (outguide).

\section{d. Pembahasan}

\section{Distribusi Frekuensi Berkas Rekam Medis duplikasi}

Berdasarkan hasil penelitian yang dilakukan selama 3 hari terdapat duplikasi penomoran rekam medis pasien sebanyak 49 berkas rekam medis, hal ini dikarenakan sistem yang digunakan dirumah sakit umum daerah tais masih menggunakan sistem manual dan sistem registrasi pada pendaftaran pasien petugas rekam medis tidak memiliki bank nomor. Nomor rekam medis hanya tercantum di dalam buku register pasien, ketika pasien tidak membawa kartu berobat maka petugas hanya mencarinya dibuku register pasien, dikarenakan Rumah Sakit Umum Daerah Taistidak memiliki tracer (outguide), jika identitas pasien tidak ditemukan maka petugas memberikan nomor rekam medis yang baru. Dan ketika pasien diberikan nomor rekam medis baru petugas sering lupa memcatat dibuku register pendaftaran maka dari itu lah sering terjadinya duplikasi nomor rekam medis.

Akibat terjadinya duplikasi berkas rekam medis yaitu pelayanan terhambat karena lamanya pencarian berkas rekam medis, ketika pasien membawa kartu berobat baru dan yang lama maka petugas harus memutuskan 1 nomor rekam medis yang dipakai, kemudian dokter juga sulit untuk melihat diagnosa pasien ketika pasien diberikan nomor rekam medis yang baru. Dan kebutuhan rak akan semakin meningkat jika tingginya angka duplikasi berkas rekam medis setiap tahunya.

Menurut kamus Besar Bahasa Indonesia, Duplikasi adaah peulangan, keadaan rangkap dua tiga helai melekat menjadi satu, duplikasi penomoran adalah pengulangan dua tiga kali pencatatan nomor yang sama, duplikasi nomor 
rekam medis adalah peulanagn nomor rekam medis yang sama dengan identitas yang berbeda.

Menurut Ica Faiqatul Hikmah, 2013 dampak duplikasi penomoran berkas rekam medis dapat mengakibatkan informasi medis tidak kesinambungan dan menunjukan mutu rekam medis yang kurang baik.

\section{Distribusi frekuensi tingkat pendidikan petugas}

Dari hasil wawancara yang dilakukan kepada 1 orang kepala ruangan dan 4 orang petugas rekam medis, di dapatkan data bahwa jumlah petugas rekam medis berjumlah 12 orang, petugas yang berlatar belakang pendidikan D3 rekam medis hanya 1 orang, 11 lainya hanya berlatar belakang D3 kesehatan, S1 kesehatan, S1 pendidikan, SMA. Dengan minimnya petugas yang berkualitas pendidikan rekam medis, maka menjadi faktor terjadinya duplikasi penomoran rekam medis, hal ini dikarenakan petugas kurang mengetahui dan kurang memperhatikan tentang sistem penomoran rekam medis.

Pendidikan adalah salah suatu usaha mengembangkan kepribadian dan kemampuan di dalam dan di luar sekolah dan berlangsung seumur hidup. Pendidikan mempengaruhi proses belajar, makin tinggi pendidikan sesorang mekin mudah orang tersebut untuk menerima informasi. Dengan pendidikan tinggi maka seseorang akan cendrung untuk mendapatkan informasi yang masuk semakin banyak pula pengetahuan yang didapat tentang kesehatan. pengetahuan sangat erat kaitanya dengan pendidikan tinggi maka orang tersebut akan semakin luas pengetahuanya. Namun perlu diletakan bahwa seorang yang berpendidikan rendah tidak berarti mutlak pengetahuan rendah pula. Peningkatan pengetahuan tidak mutlak diperoleh di pendidikan formal, akan tetapi juga dapat diperoleh pada pendidikan non formal. Pengetahuan seorang tentang suatu objek tertentu. Semakin banyak aspek dari objek yang diketahui, akan menimbulkan sikap positif terhadap objek tertentu (Notoadmojo, 2010).

Dampak dari tingkat pendidikan tersebut bisa berpengaruh dengan terjadinya duplikasi penomoran berkas rekam medis, karna belum menciptakan pelayanan yang sesuai dengan standar yang berlaku dan tidak pahamm terhadap tugas pokok dan fungi di dalam pelayanan rekam medis.

\section{Penggunaan Tracer (outguide)}

Dari hasil wawancara yang dilakukan peneliti kepada petugas rekam medis bahwa diruangan penyimpanan berkas rekam medis 
belum menggunakan petunjuk keluar tracer (outguide) sebagai penganti berkas rekam medis yang dipinjam atau dikeluarkan dari rak penyimpanan. Mereka hanya menggunakan buku register sebagai alat pengendali berkas rekam medis yang keluar dari rak penyimpanan. Tidak adanya tracer (outguide) dikerenakan sarana dan prasarana belum memadai dan petugas rekam medis tidak perna mengikuti pelatihan atau kegiatan bimbingan mengenai rekam medis sehingga kurangnya pengetahuan petugas terhadap tracer (outguide).

Berdasarkan teori yang ada petunjuk keluar tracer (outguide) tetap berada di rak penyimpanan sampai rekam medis yang dipinjam dikeluarkan dan disimpan kembali (Huffman,2008). Petunjuk keluar tracer (outguide) adalah folder plastik yang digunakan ditempat rekam medis ketika rekam medis telah dipindahkan dari rak penyimpanan (Abdelhak, 2001).

Dampak dari tidak adanya tracer (outguide) bisa menyebabkan terjadinya duplikasi berkas rekam medis, karena ketika berkas rekam medis tidak ditemukan dirak penyimanan dan di buku register maka petugas membuatkan berkas rekam medis baru dengan nomor rekam medis yang baru juga.

\section{SIMPULAN}

Berdasarkan hasil dan pembahasan mengenai bagaimana analisis faktor terjadinya duplikasi berkas rekam medis di ruangan filling di RSUD Tais Kabupaten Seluma dapat disimpulkan :

1. Dari hasil penelitian diketahui dari 233 berkas rekam medis yang di teliti terdapat 49 berkas rekam medis yang duplikasi penomoranya, dan 184 berkas rekam medis yang tidak terjadinya duplikasi.

2. Pada Rumah Sakit Umum Daerah Tais petugas rekam medis berjumlah 12 orang, dan hanya 1 orang peugas yang berlatar belakang pendidikan D3 rekam medis dengan minmnya SDM yang berlatar belakang D3 rekam medis kurangnya pengetahuan petugas tentang rekam medis, dan dapat menjadikan salah satu penyebab terjadinya duplikasi nomor rekam medis.

3. Di Rumah Sakit Umum Daerah Tais belum memiliki tracer (outguide) sebagai penganti berkas rekam medis yang dipinjam atau dikeluarkan dari rak penyimpanan, tetapi tracer (outguide) sudah dalam perencanaan.

\section{DAFTAR PUSTAKA}


Agustina. 2011.Perancangan Dan Prosedur Penggunaan Tracer Petunjuk Keluar (Outguide) untuk menyimpan rekam medis rawat jalan di BLUED RS RATU ZALECHA MARTAPURA. Banjarbaru: Stikes Husadaborneo.

Ajzen, Fishbein. 1995. Konsep Dalam Model (Techmologi Acceptance Model-TAM). Jakarta.

Budi, S C. 2011. Manajemen Unit Kerja Rekam Medis. Yogyakarta.

Budi S C. 2015. Pentingnya Tracer Sebagai Kartu Pelacak Berkas Rekam Medis Yang Keluar Dari rak Penyimpanan. Yogyakarta. Indonesia Jurnal Of Comuniti Enggagement Vol. 01, No. 01.

Departemen Kesehatan Republik Indonesia. 1997. Pedoman Pengelolahan Rekam Medis Rumah Sakit Di Indonesia Revisi I. Jakarta.

Depkes RI. 1997. Pedoman Pengelolahan Rekam Medis Rumah Sakit Di Indonesia. Jakarta.

Direktorat Jendral Pelayananmedik. Departemen Kesehatan Republik Indonesia. Petunjuk Teknis Penyelengaraan Rekam Medis. Jakarta, 1991.

Hatta, Gemala. 2008. Pedoman Manajemen Kesehehatan Disarana Pelayanan Kesehatan. Jakarta. Universitas Indonesia

Huffman, Edna K. 1994. Health Information Organization. Illios: Physicians Record Company. Jakarta
Hastono. 2007. Analisa Data Kesehatan. jakarta. FKM. UI. Sugiono

Mentri Kesehatan RI. 2008. Peraturan Menteri Kesehatan Republik Indonesia Nomor. 269/Menkes/Per/2008 tentang rekam medis. Jakarta: Departemen Kesehatan RI.

Notoaddmojo . 1997. Tujuan perencanaan suatu sistem informasi. Jakarta.

Pengertian rumah sakit s.I : Peraturan Menteri Kesehatan Republik Indonesia, 2010.340/MENKES/PER/III.

Peraturan mentri kesehatan Republik indonesia no. 269 tahun 2008 tentang rekam medis. Jakatra.

Riwidikdo, andoko. (2009). Statistik kesehatan : belajar mudah analisis data dalam penelitian kesehatan. Yogyakarta: Mitra Candikia Press.

Rustianto, Erly, 2009, Etika Propesi perekam medis \& informasi kesehatan. Yogyakarta: Graha ilmu.

Sastroasmoro, S dan Ismael, S. 2010. DasarDasar Metodologi Penelitian Klinis. Jakarta: Sagung seto.

Sugiono. 2005. Pengertian deskriptif. Jakarta.

Vita Mardiyarni. 2013. Tinjauan Tingkat Kejadian Missfile Dan Faktor-Faktor Penyebabna Di Filling

RSUD Sunan Kalijaga Kabupaten Damak Triwulan 1 Tahun. 